\title{
Editorial
}

\section{Conferences teaching and training---our future}

It's the season of festivities and conferences. We meet friends and colleagues exchange notes learn new ideas and benchmark our work. Having just come back from two meetings of the Hand and Plastic surgeons I am wondering about this and other things. Conferences certainly help to increase our knowledge and skills, allow us to put questions to authorities in the field, for clarifying doubts and most important, allow junior surgeons to widen their horizons significantly. Teaching is thus the prime function of our meetings in addition to socializing with colleagues. This brings me to the point of this editorial.

Teaching in Plastic Surgery is essential for our survival as a species, unless we teach and create new Plastic Surgeons there will be no peer group left and no one to carry forward our legacy of a glorious specialty. It appears however that teaching is now in a bit of a crisis-at least in the teaching institutions. This is a shame but we have to face up to facts, not to lament them but to find/ suggest solutions.

Teaching units are facing two main problems, the exodus of qualified teachers and the inability to make our departments truly super specialty. The exodus is now definite. It is increasingly rare to see intense competition for jobs in Government Medical College departments. With the existing pay structure and the poor working conditions in general, it is going to be very difficult to attract and retain talent. If you add to that arbitrary transfers and bureaucratic interference then the combination is even more unattractive for new young teachers keen to share their knowledge with students.

The second problem is of skill sets. Today a good teaching unit ought to have a specialist in Cleft and Craniofacial Surgery, Hand, Reconstructive Microsurgery, Aesthetic Surgery, Burns and of course a good generalist at a senior level at the very least. The trainees ought to be spending 4 to 6 months with each of these persons in the unit so that they come out as well rounded products. With the present situation we are lucky if we can retain three good people in many teaching units. Training invariably suffers and we then see students seeking specialty training in outside centres after their M.Ch. This is not bad in itself, but remains uncertain and unstructured.

The only viable solution is to give up rigid definitions of teachers and lobby hard with the powers that be to allow visiting Professors. There will be many who will be willing to give back to the fraternity and their alma maters. If we move quickly and bring in these people on a voluntary basis purely for their expertise without the hassle of myriad rules and regulations and bureaucratic strings we truly will usher in a sudden quantum change in our inputs to Post Graduates. It is time the Association becomes a lobbying instrument to further the larger interests of the Plastic Surgical community in teaching and training.

Mukund Thatte

Editor, Indian Journal of Plastic Surgery 